\title{
Relationship between muscle mass and neuromuscular function in the muscular strength of elderly women practicing and non-practicing physical activities
}

\author{
Relação entre massa e função neuromuscular na força de mullheres idosas praticantes e não \\ praticantes de atividades física
}

Relación entre masa muscular y función neuromuscular en la fuerza de mujeres mayores que

practican y no actividades física

Received: 11/28/2021 | Reviewed: 12/07/2021 | Accept: 12/15/2021| Published: 12/22/2021

\author{
Nathalie De Almeida Silva \\ ORCID: https://orcid.org/0000-0002-9707-9661 \\ Universidade Estadual da Paraíba, Brazil \\ E-mail: nathaliegmr@yahoo.com.br \\ Cledinaldo Lira Júnior \\ ORCID: https://orcid.org/0000-0002-2863-5513 \\ Universidade Estadual da Paraíba, Brazil \\ E-mail: junior_lira16@hotmail.com \\ Maria Goretti Da Cunha Lisboa \\ ORCID: https://orcid.org/0000-0002-2552-2054 \\ Universidade Estadual da Paraíba, Brazil \\ E-mail:gorettilisboa@hotmail.com \\ Jozilma De Medeiros Gonzaga \\ ORCID: https://orcid.org/0000-0002-2552-2054 \\ Universidade Estadual da Paraíba, Brazil \\ E-mail:jozilmam@uol.com.br \\ Danilo De Almeida Vasconcelos \\ ORCID: https://orcid.org/0000-0003-3491-0902 \\ Universidade Estadual da Paraíba, Brazil \\ E-mail:danilovasconcelos@servidor.uepb.edu.br \\ Tarciana Nobre De Menezes \\ ORCID: https://orcid.org/0000-0003-1784-3218 \\ Universidade Estadual da Paraíba, Brazil \\ E-mail:tnmenezes@yahoo.com.br
}

\begin{abstract}
Objective. To verify the correlation between muscle mass and neuromuscular function in muscle strength of women practicing and not practicing physical activities. Methods. This is a cross-sectional study conducted with older women (60 and over), physically active (fa) and physically inactive (fi). The muscle strength of the upper limb (handgrip strength - hgs; resisfor test) and lower limb (30 second chair stand test) were evaluated; as well as muscle mass (calf circumference - cc); and neuromuscular activity (semg) of the following muscles: flexor carpi radialis (fcr) and biceps brachii (bb) (upper limb); vastus lateralis (vl), vastus medialis (vm) and tibialis anterior (ta) (lower limb). The student $\mathrm{t}$ test and multiple linear regression were used (95\%; $\mathrm{p}<.05)$. Results. Overall, 59 women were evaluated $(71.5 \pm 7.1$ years), $31 \mathrm{fa}$ and $28 \mathrm{fi}$. Fa women had significantly better values in dynamic muscular strength tests of the upper $(\mathrm{p}=.001)$ and lower limbs $(\mathrm{p}<.0001)$. There was no significant difference in muscle mass between groups. After adjustment for covariates, there was relationship between $\mathrm{cc}$ and activity of fcr muscle with hgs $\left(\mathrm{r}^{2}{ }_{\text {adj. }}=0.64\right)$, and $\mathrm{cc}$ with the 30 second chair stand test $\left(r^{2}\right.$ adj. $\left.=.39\right)$ in fa women. Among fi women, there was significant correlation between activity of fcr muscle and $\mathrm{hgs}\left(\mathrm{r}_{\text {adj. }}^{2}=.35\right)$ and $\mathrm{cc}$ and neural activity of fcr with resisfor $\left(\mathrm{r}^{2}\right.$ adj. $\left.=.66\right)$. Conclusion. Physical exercise was related to higher dynamic muscle strength. Differences in the relationship between muscle mass and neuromuscular activity with strength in each test indicate physiological differences for each strength exercise applied.
\end{abstract}

Keywords: Elderly; Muscle mass; Neuromuscular function; Muscle strength; Physical exercise.

\section{Resumo}

Objetivo. Verificar a correlação entre massa e função neuromuscular na força de mulheres praticantes e não praticantes de atividades físicas. Métodos. Trata-se de um estudo transversal realizado com mulheres idosas (60 anos ou mais), fisicamente ativas (FA) e fisicamente inativas (FI). Foram avaliadas as forças musculares do membro superior (força de preensão manual - FPM; teste RESISFOR) e do membro inferior (teste de pé de cadeira de 30 
segundos); bem como a massa muscular (circunferência da panturrilha - CC); e atividade neuromuscular (sEMG) dos seguintes músculos: flexor radial do carpo (FCR) e bíceps braquial (BB) (membro superior); vasto lateral (VL), vasto medial (VM) e tibial anterior (TA) (membro inferior). O teste t de Student e a regressão linear múltipla foram usados (95\%; $\mathrm{p}<0,05)$. Resultados. No geral, foram avaliadas 59 mulheres (71,5 \pm 7,1 anos), 31 FA e 28 FI. Mulheres FA tiveram valores significativamente melhores em testes de força muscular dinâmica dos membros superiores $(\mathrm{p}=$ $0,001)$ e inferiores $(p<0,0001)$. Não houve diferença significativa na massa muscular entre os grupos. Após o ajuste para covariáveis, houve relação entre CC e atividade do músculo FCR com FPM (R2adj. = 0,64), e CC com o teste de pé de cadeira de 30 segundos (R2adj. = 0,39) em mulheres com AF. Entre as mulheres FI, houve correlação significativa entre a atividade do músculo FCR e HGS (R2adj. = .35) e CC e atividade neural de FCR com RESISFOR (R2adj. = .66). Conclusão. O exercício físico foi relacionado a maior força muscular dinâmica. Diferenças na relação entre a massa muscular e a atividade neuromuscular com a força em cada teste indicam diferenças fisiológicas para cada exercício de força aplicado.

Palavras-chave: Idoso; Massa muscular; Função neuromuscular; Força muscular; Exercício físico.

\section{Resumen}

Objetivo. Verificar una correlación entre masa y función neuromuscular con la fuerza de mulheres practicantes y no practicantes de actividades físicas. Métodos. Trata-se de um estudo transversal realizado con mulheres idosas (60 anos ou mais), fisicamente ativas (FA) e fisicamente inativas (FI). Foram avaliadas as forças musculares do membro superior (força de preensão manual - FPM; teste RESISFOR) e do membro inferior (teste de pé de cadeira de 30 segundos); bem como a massa muscular (circunferência da panturrilha - CC); e atividade neuromuscular (sEMG) dos seguintes músculos: flexor radial del carpo (FCR) e bíceps braquial (BB) (membro superior); vasto lateral (VL), vasto medial (VM) y tibial anterior (TA) (membro inferior). O teste $t$ de Student e una regresión lineal múltipla foram usados (95\%; p <0,05). Resultados. No general, foram avaliadas 59 mulheres (71,5 \pm 7,1 años), 31 FA e 28 FI. Mulheres FA tiveram valores significativamente melhores em testículos de fuerza muscular dinámica dos membros superiores $(\mathrm{p}=0,001)$ e inferiores $(\mathrm{p}<0,0001)$. Não houve diferença significativa na massa muscular entre os grupos. Após o ajuste para covariáveis, houve relação entre CC e atividade do músculo FCR com FPM (R2adj. = 0,64), e CC com o teste de pé de cadeira de 30 segundos (R2adj. = 0,39) em mulheres com AF. Entre como mulheres FI, houve correlação significativa entre a atividade do músculo FCR e HGS (R2adj. = .35) e CC e atividade neural de FCR com RESISFOR (R2adj. = .66). Conclusão. O exercício físico foi relacionado a maior força muscular dinâmica. Diferenças na relação entre una massa muscular e una atividade neuromuscular com a força em cada teste indicam diferenças fisiológicas para cada ejercicio de força aplicado.

Palabras clave: Idoso; Massa muscular; Função neuromuscular; Força muscular; Ejercicio físico.

\section{Introduction}

The aging process is associated with structural and functional changes in different systems, which may be explained by genetic factors, multiple morbidities, and non-genetic factors; as nutrition, lifestyle, and physical activity (Kirkwood, 2017). The physical impairment may contribute to the occurrence of physical limitations, dependence and risk of institutionalization. Loss of physical strength is, therefore, considered an indicator of biological aging (Clouston et al., 2013). Muscle strength has been used to evaluate the physical performance of the elderly because of its relationship with functional capacity and physical independence (Reid et al., 2014).

Muscle strength may decrease to a level that starts to restrict the ability to perform everyday activities. So, a comprehensive follow-up of functional impairment rates and its relationship with disability over time may be a good strategy to find out which are the factors to contribute to a greater or lesser risk of disability and, to also, to provide support to promote strategies to a healthier aging process (Tomás et al., 2018).

Advancing age brings changes in body composition (Santos et al., 2017; Peter, 2018) and neuromuscular function (Peter, 2018). Changes in body composition are characterized by accumulation and redistribution of fat mass and decreasing lean mass, with more significant reduction of skeletal muscle (Santos et al., 2017). Reduced muscle mass is related to anatomical and physiological changes such as atrophy and hypoplasia of muscle fibers, rearrangement of muscle architecture (Larsson et al., 2019).

Aging is related also to important changes in the nervous system. It influences the properties of nerve discharge by 
reducing the size, quantity and frequency of motor units recruited to movement, and the number of motor neurons; and causing losses in the process of excitation-contraction coupling (Larsson et al., 2019). The set of changes in the nervous coordination and in the musculoskeletal system have influence on neuromuscular function and seem to contribute to reduced muscle strength in the elderly (Reid et al., 2014).

In recent years, it has been observed that physical activity improves different aspects of physical functioning (Angulo et al., 2020). However, with the advancement of age, less readiness to physical activity has been observed among older people, especially among women (Tomás et al., 2018). Furthermore, physical activity has been negatively associated with the decline of dynamic muscle strength of upper and lower limbs, flexibility, agility and resistance (Milanovic et al., 2013).

Given the above, it is important to clarify if loss of muscle mass or changes in neuromuscular function influence the generation of muscle strength, considering the possible influence of stakeholder issues, such as physical activity, in this relationship. Given the importance of muscle strength as a potential risk factor for functional dependence in the elderly population, further clarification on this issue is relevant for the areas of geriatrics, gerontology and public health. Thus, it is possible to collaborate with the development of specific preventive actions in groups and rehabilitation of physical problems, using specific interventions for individual consultations. Thus, the objective of this study was to verify the correlation between muscle mass and neuromuscular function in muscle strength of women practicing and not practicing physical activities.

\section{Methodology}

This is a cross-sectional study with collection of primary data. It is part of a larger research conducted in the city of Campina Grande/PB, Brazil, in the period from March to November 2015.

This research is regulated in accordance with the provisions of the Declaration of Helsinki. The larger research of which this study is part was approved by the Research Ethics Committee (REC) of the State University of Paraiba (UEPB) (CAAE: 33840514.8.0000.5187). Elderly participants received information about the study and when they agreed to participate, they signed the Informed Consent Instrument, according to Resolution $n^{\circ} .466$ of the National Health Council of December 12, 2012.

\subsection{Sample}

Older women (60 years and over) living in the city of Campina Grande, practitioners and non-practitioners of physical activity, were included in this study. The sample was non probabilistic. The elderly practitioners of physical activity (PFA) were selected among older participants of the Program Open University in Free Time of the UEPB, which offers practical lessons of physical activity in the modalities general fitness and weight training. Of the 47 elderly women enrolled in the program, 36 were eligible to participate in the research.

Elderly that was non-practitioners of physical activity (NPFA) were selected from community groups located in the city of Campina Grande/PB. According to information from the Municipal Social Welfare, there were 13 groups assisted by the secretariat in 2015. Among these, the groups located in the rural town without regular meetings and those with some program of physical activity for seniors were excluded. Thus, seven groups were included in the study. All elderly women were informed of the research content and the ones who agreed to participate were submitted to the Modified Baecke Questionnaire for the Elderly (MBQE) (Paulo, 2009) to identify those who were not physically active. Thus, 36 elderlies were considered eligible for the research.

These elderlies were chosen due to the fact that these reference groups provide emotional support, self-esteem and well-being to the elderly, favoring the maintenance of physical and mental health, as they provide social interaction, sharing of 
ideas and experience, and the development of occupational and leisure activities. As the groups are intended for physical activity, these elderlies are characterized as being socially active, promoting the homogeneity of the sample and reducing the possible effects that social and emotional factors may have on the physical performance.

In the case of NPFA, elderly who reported not having done any physical activity in the sessions of "sports" and "leisure activities" during application of the MBQE were included in the study. Elderly women with clinical diagnosis of any neurological disease and deformities or trauma-orthopedic limitations that prevented them from walking without assistance, sitting down and standing up without help, and carrying out weight lifting with the upper limbs, were excluded from the sample. Furthermore, elderly women that had undergone surgery in the arms or hands in the three months prior to collection were excluded from the handgrip test. Among elderly PFA, those who did not attend at least $75 \%$ of the activities of the program in the last six months were excluded.

\subsection{Muscle strength}

In order to evaluate muscle strength, three tests were used: a) hand-grip strength (HGS); b) strength and endurance of the upper limbs; c) "sitting down and standing up" test. Before each test, the elderly was asked about in which member they considered to have more strength (dominant) and they received explanations and practical demonstrations in order to ensure the proper implementation of the task without incurring any risk to them.

To evaluate the HGS (isometric strength of the upper limb), a manual hydraulic dynamometer (Dynamometer Takei Kiki Kogyo ${ }^{\circledR}$ TK 1201, Japan) was used and adjusted for each individual according to the size of hands. During the execution of the test, the elderly sat with the elbow supported on a table, forearm extended forward, palm upwards and, then, they were asked to exercise the greatest possible prehension (Rantanen et al., 1998). This procedure was performed once.

For the evaluation of upper limb dynamic force, the test of strength and endurance of the upper limbs (RESISFOR) was applied. This is part of the American Alliance for Health Physical Education Recreation and Dance (AAHPERD) test set, which consists of motor tests specific to the elderly population. To perform the RESISFOR test, a dumbbell of $2 \mathrm{~kg}$ weight, recommended for the application of the test in women, was used. The elderly was positioned sitting in a chair (without arms), and the halter was placed in the dominant hand, parallel to the ground with one end facing forward. When the assessor signaled the command "go", the elderly woman would contract biceps, performing a full flexion of the elbow, and then returned to the starting position. The test result considered the number of full movements carried out in 30 seconds (Osness \& Council on Aging and Adult Development (U.S.), 1990).

To perform the 30-second chair stand test (30-s CST), a non-support chair was used for arms. The elderly woman would be told to sit in the middle of the chair seat, with her back straight, feet flat on the floor and arms crossed against her chest. To the signal "go", the elderly woman should get up, totally standing up and then return the fully seated position. The test results considered the number of times that the participant performed the motion of sitting down and standing up in 30 seconds (Jones et al., 1999).

\subsection{Muscle mass}

For the evaluation of muscle mass, we used the value of the calf circumference (CC) $(\mathrm{cm})$, which was measured using an inelastic tape, with accuracy of $1 \mathrm{~mm}$. For the measurement of the $\mathrm{CC}$ of the elderly, this was placed in a sitting position, with the thigh forming an angle of $90^{\circ}$ with the leg. The measurement was performed on the right side, with the evaluator crouching at the side of the elderly. The measure was obtained from the wider portion of the calf region, without compressing it and with the tape perpendicular to the calf. Two measures were taken, and when the values did not coincide, a third 
measurement was performed. For the calculation of the final value, the average of the values obtained was considered (Lohman et al., 1988).

\subsection{Neuromuscular function}

Neuromuscular activity was assessed using surface electromyography (sEMG), simultaneously with the registration of muscle strength. To capture the electromyographic signals, we used an acquisition of biological signals Miotool (Miotec ${ }^{\circledR}$ ) module and a Miograph software $\left(\right.$ Miotec $\left.^{\circledR}\right)$ Calibrated with $1000 \mathrm{~Hz}$ sampling frequency, total gain of 2,000 times, $20 \mathrm{~Hz}$ high pass filter, $500 \mathrm{~Hz}$ low pass filter and notch $(60 \mathrm{~Hz})$. The electrodes were placed unilaterally in the upper and lower limbs, referred to as dominant for the elderly, according to the recommendations of the Europe Project: Surface Electroyography for non-invasive assessment of muscles (SENIAM) (The SENIAM project, 2006).

For data collection, $\mathrm{Ag} / \mathrm{AgCl}$ (Meditrace) surface electrodes in bipolar configuration with catchment area of $1 \mathrm{~cm}$ in diameter and inter-electrode distance of $2 \mathrm{~cm}$ were used. Prior to placing the electrodes, trichotomy was performed with use of disposable steel blade, and abrasion and cleaning of the skin with $70 \%$ alcohol.

For the HGS test, we measured the flexor carpi radialis (FCR). The location of the muscle was made through palpation method. For the RESISFOR test, the FCR muscles and the biceps were evaluated, and in this, the electrode was placed on the recommendation of SENIAM (The SENIAM project, 2006). In both tests, the reference electrode was placed in the radial process. In the "sitting down and standing up" test, the vastus lateralis, vastus medialis and tibialis anterior were evaluated, and the reference electrode was placed in the lateral malleolus of the limb evaluated. All electrodes were positioned according to the recommendations of the SENIAM (The SENIAM project, 2006).

Variables corresponding to the time domain: root mean square (RMS) standard and the integration EMG (IEMG) were selected for the analysis of the electromyographic signal. For this, the strength curve window during the period spent for the realization of the three tests of muscle strength was evaluated.

\subsection{Covariates}

The control variables in this study were: age (years); socioeconomic status; body mass index; cognitive state; presence of chronic diseases; and energy expenditure in daily activities, sports and leisure, in the last year.

The socioeconomic status (SES) was evaluated considering the ABA/ANEP/ABIPEME (Brazilian Advertisers Association, National Association of Research Companies and the Brazilian Association of Market Research Institutes, respectively) criterion of economic classification. This covers level of education of the elderly and ownership of items in the family. These are accounted for, resulting in a score scale that ranges from 0 to 46 points, with the lowest values corresponding to the lower SES (Associação Brasileira de Empresas e Pesquisas, 2020).

To calculate the body mass index (BMI) $\left(\mathrm{kg} / \mathrm{m}^{2}\right)$, weight and height were measured according to the techniques described by Lohman et al. (1988) Weight ( $\mathrm{kg}$ ) was measured in portable digital scale (TANITA UM080) for up to $150 \mathrm{~kg}$ and sensitivity of $100 \mathrm{~g}$. Height (m) was measured in portable stadiometer (Accurate Height).

Cognitive status was assessed using the Mini Mental State Examination (MMSE), which assesses global cognitive function. The MMSE is composed of 11 items with scores ranging from zero to 30, adjusted for schooling (Brucki, Nitrini, Caramelli, Bertolucci, \& Okamoto, 2003). Values closer to zero correspond to bad cognition and values closer to 30, good cognition. MMSE scores were considered for the analysis of results in this study.

Data on the presence of chronic diseases were obtained by self-report, with the response of the elderly to the question: "Has a doctor or other health professional ever said you have any of these diseases?". Three conditions were considered: high 
blood pressure (yes, no); diabetes (yes, no); and arthritis/osteoarthritis/rheumatism (yes, no).

Energy expenditure was obtained through the MBQE. This questionnaire is a recall of the last year consisting of questions related to three areas: a) activities of daily living, assessed by 10 questions, each with four options, obtaining at the end a value that can range from 0 to 30; b) sports activities and c) leisure activities. The latter are obtained by questioning what activities the elderly carried out, and for each activity, the following aspects are considered: intensity, amount of hours per week and number of months. The intensity is determined in metabolic equivalent (MET), pre-established for each activity. The final MBQE score was obtained with the sum of values in each domain (Paulo, 2009). The final score of this variable was used to control the results in NPFA elderly.

\subsection{Statistical procedures}

Initially, data were submitted to double entry, and validation of banks was verified by the tool "validate", through the Epi Info 6.04 statistical program (Centers for Disease controland Prevention, Atlanta, USA). All analyses were stratified according to physical activity, separating the two groups: PFA and NPFA. The statistical information was obtained through the statistical application SPSS 22.0 (IBM Corp., Armonk, United States).

The Kolmogorov-Smirnov test was used to test the normality of data. Mean and standard deviation are presented for numerical data, and frequency distribution for categorical data. We used the Student $t$-test to compare the average values of muscle mass, muscle strength, neuromuscular activity and covariates among PFA and NPFA women.

The correlation of muscle mass, neuromuscular activity and other variables with muscle strength of upper limbs (HGS, RESISFOR) and lower limbs ("sitting down and standing up test") was verified through Pearson correlation test and bivariate regression. To test the concomitant relationship of muscle and neuromuscular function with muscle strength, a multiple linear regression was fitted through the forward stepwise method. In the final model, the variables with $\mathrm{p}$ (significance level) $<0.05$ were kept. All models were subjected to residue analysis through the multicollinearity test (VIF), and evaluation of homoscedasticity. A confidence interval of 95\% (CI 95\%) was considered for all analyses.

\section{Results}

Among the 72 elderly selected for the survey, 13 did not complete the study protocol, resulting in a sample of 59 elderly. Among these, 31 were PFA and 28, NPFA. The average age of the elderly in this study was 71.5 years $( \pm 7.1)$, ranging from 60 to 91 years. According to the data presented in table 1, there was no significant difference in muscle mass between PFA and NPFA elderly $(p=0.242)$. As for muscle strength, it was observed that the PFA elderly had significantly higher average values in RESISFOR test (20.7 times) and in the 30-s CST (16.2 times) in relation to NPFA elderly (15.7 and 15, 5 times, respectively). Still, table 1 shows the mean values of neuromuscular function, in which significant difference was observed only in the average value of the RESISFOR tests for the flexor carpi radialis and biceps brachii. 
Table 1. Comparison of muscle mass. muscular strength and neuromuscular function among women practicing and non-practicing physical activity. Campina Grande/PB. Brazil. 2015.

\begin{tabular}{|c|c|c|c|c|c|}
\hline & \multicolumn{5}{|c|}{ PRACTICING PHYSICAL ACTIVITY } \\
\hline & \multicolumn{2}{|c|}{ YES } & \multicolumn{2}{|c|}{ NO } & \multirow[b]{2}{*}{$p$} \\
\hline & Mean & SD & Mean & SD & \\
\hline \multicolumn{6}{|l|}{ MUSCLE MASS } \\
\hline $\mathrm{CC}(\mathrm{cm})$ & 36.8 & 4.47 & 35.6 & 3.10 & 0.242 \\
\hline \multicolumn{6}{|c|}{ MUSCULAR STRENGTH } \\
\hline HGS $(\mathrm{Kg})$ & 23.1 & 4.28 & 22.5 & 4.66 & 0.593 \\
\hline RESISFOR (times) & 20.7 & 6.09 & 15.7 & 4.72 & $0.001 *$ \\
\hline 30-s CST (times) & 16.2 & 4.05 & 12.5 & 3.22 & $<0.0001^{*}$ \\
\hline \multicolumn{6}{|c|}{ NEUROMUSCULAR FUNCTION } \\
\hline \multicolumn{6}{|l|}{ HGS - FCR } \\
\hline RMSs (\%) & 54.9 & 15.38 & 59.9 & 12.60 & 0.205 \\
\hline $\operatorname{IEMG}(\delta)$ & 2.8 & 0.89 & 2.9 & 1.55 & 0.877 \\
\hline \multicolumn{6}{|l|}{ RESISFOR - FCR } \\
\hline RMSs (\%) & 39.9 & 9.46 & 36.2 & 8.11 & 0.128 \\
\hline $\operatorname{IEMG}\left(\int\right)$ & 2.3 & 1.74 & 3.61 & 2.10 & $0.017^{*}$ \\
\hline \multicolumn{6}{|l|}{ RESISFOR - BB } \\
\hline RMSs (\%) & 44.0 & 10.05 & 38.1 & 8.72 & $0.024^{*}$ \\
\hline $\operatorname{IEMG}\left(\int\right)$ & 2.2 & 1.29 & 3.94 & 3.20 & $0.013^{*}$ \\
\hline \multicolumn{6}{|l|}{ 30-s CST - VL } \\
\hline RMSs (\%) & 30.1 & 6.97 & 30.8 & 6.10 & 0.688 \\
\hline $\operatorname{IEMG}(\delta)$ & 4.4 & 1.94 & 4.5 & 2.33 & 0.908 \\
\hline \multicolumn{6}{|l|}{ 30-s CST - VM } \\
\hline RMSs (\%) & 29.6 & 5.70 & 29.1 & 5.89 & 0.732 \\
\hline $\operatorname{IEMG}(\delta)$ & 4.1 & 1.69 & 3.4 & 1.65 & 0.134 \\
\hline \multicolumn{6}{|l|}{ 30-s CST - TA } \\
\hline RMSs (\%) & 38.4 & 6.95 & 36.4 & 8.71 & 0.343 \\
\hline $\operatorname{IEMG}(\Omega)$ & 6.0 & 2.55 & 4.6 & 2.73 & 0.061 \\
\hline
\end{tabular}

$\mathrm{SD}=$ standard deviation; $*=\mathrm{p}<0.05 ; \mathrm{CC}=$ calf circumference; HGS $=$ hand grip strength; RESISFOR $=$ test of strength and endurance of the upper limbs; 30-s CST $=30$-second chair stand test; FCR $=$ flexor carpi radialis; $\mathrm{BB}=$ biceps brachii; VL $=$ vastus lateralis; $\mathrm{VM}=$ vastus medialis; $\mathrm{TA}=$ tibialis anterior; RMSs $=$ root mean square standard; IEMG = integration EMG. Source: Authors

The bivariate correlation of muscle mass and neuromuscular function with muscle strength in PFA women is presented in table 2 . The calf circumference showed a significant correlation with the HGS scores $\left(\mathrm{R}^{2}=0.20 ; \mathrm{p}=0.013\right)$ and in the 30-s CST $\left(\mathrm{R}^{2}=0.20 ; \mathrm{p}=0.015\right)$. There was a significant correlation between the average value of neuromuscular function only with the scores of the 30 -s CST in one of the evaluated muscles (vastus lateralis: $\mathrm{R}^{2}=0.32 ; \mathrm{p}=0.002$ ). There was no significant relationship of neuromuscular activity with the HGS and RESISFOR tests. 
Table 2. Bivariate correlation of muscle mass and neuromuscular function with muscle strength in elderly women practicing physical activity. Campina Grande/PB. Brazil. 2015.

\begin{tabular}{|c|c|c|c|c|c|c|}
\hline Variables & R Pearson & $p^{\#}$ & $\mathbf{R}^{2}$ & $\boldsymbol{\beta}$ & $\mathbf{F}$ & $\boldsymbol{p}^{\# \#}$ \\
\hline \multicolumn{7}{|l|}{ HGS } \\
\hline $\mathbf{C C}(\mathrm{cm})$ & 0.44 & $0.013^{*}$ & 0.20 & 0.422 & 7.023 & $0.013 *$ \\
\hline \multicolumn{7}{|c|}{ Flexor Carpi Radialis } \\
\hline RMSs (\%) & 0.21 & 0.317 & 0.05 & 0.061 & 1.047 & 0.317 \\
\hline $\operatorname{IEMG}(\Omega)$ & -0.17 & 0.440 & 0.03 & -0.823 & 0.617 & 0.440 \\
\hline \multicolumn{7}{|l|}{ RESISFOR } \\
\hline $\mathbf{C C}(\mathrm{cm})$ & 0.13 & 0.504 & 0.02 & 0.140 & 0.458 & 0.504 \\
\hline \multicolumn{7}{|c|}{ Flexor Carpi Radialis } \\
\hline RMSs (\%) & 0.14 & 0.478 & 0.02 & 0.075 & 0.518 & 0.478 \\
\hline $\operatorname{IEMG}(\delta)$ & 0.29 & 0.125 & 0.09 & 0.845 & 2.501 & 0.125 \\
\hline \multicolumn{7}{|l|}{ Biceps Brachii } \\
\hline RMSs (\%) & 0.09 & 0.627 & 0.01 & 0.048 & 0.242 & 0.627 \\
\hline $\operatorname{IEMG}(\Omega)$ & 0.12 & 0.950 & $<0.0001$ & 0.048 & 0.004 & 0.950 \\
\hline \multicolumn{7}{|l|}{ 30-s CST } \\
\hline $\mathbf{C C}(\mathrm{cm})$ & -0.46 & $0.015^{*}$ & 0.21 & -0.342 & 6.857 & $0.015^{*}$ \\
\hline \multicolumn{7}{|l|}{ Vastus Lateralis } \\
\hline RMSs (\%) & 0.23 & 0.236 & 0.05 & 0.111 & 1.468 & 0.236 \\
\hline $\operatorname{IEMG}(\Omega)$ & 0.56 & $0.002 *$ & 0.32 & 0.986 & 12.018 & $0.002 *$ \\
\hline \multicolumn{7}{|l|}{ Vastus Medialis } \\
\hline RMSs (\%) & 0.27 & 0.173 & 0.07 & 0.157 & 1.963 & 0.173 \\
\hline $\operatorname{IEMG}(\Omega)$ & 0.02 & 0.918 & $<0.0001$ & 0.041 & 0.011 & 0.918 \\
\hline \multicolumn{7}{|l|}{ Tibialis Anterior } \\
\hline RMSs (\%) & 0.02 & 0.913 & $<0.0001$ & 0.011 & 0.012 & 0.913 \\
\hline $\operatorname{IEMG}(\delta)$ & 0.23 & 0.238 & 0.05 & 0.307 & 1.459 & 0.238 \\
\hline
\end{tabular}

$\mathrm{R}$ Pearson $=$ Pearson correlation coefficient; $\mathrm{p}^{\#}=$ significance level (Pearson correlation); $\mathrm{R}^{2}=$ determination coefficient; $\beta=$ regression coefficient; $\mathrm{F}=\mathrm{F}$ distribution $\left(\mathrm{F}\right.$ of Fisher-Snedecor); $\mathrm{p}^{\# \#}=$ significance level (simple linear regression); $*=\mathrm{p}<0.05$; $\mathrm{CC}=$ calf circumference; HGS = hand grip strength; RESISFOR = test of strength and endurance of the upper limbs; 30-s CST $=30$-second chair stand test; RMSs = root mean square standard; IEMG = integration EMG. Source: Authors.

Table 3 shows the values of the bivariate correlation of muscle mass and neuromuscular function with muscle strength in NPFA women. The calf circumference showed a significant correlation with all muscular strength tests $(p<0.05)$. There was no significant correlation of neuromuscular function and strength tests of the upper and lower limbs. 
Table 3. Bivariate correlation of muscle mass and neuromuscular function with muscle strength in elderly women non-practicing physical activity. Campina Grande/PB. Brazil. 2015.

\begin{tabular}{|c|c|c|c|c|c|c|}
\hline Variáveis & R Pearson & $p^{\#}$ & $\mathbf{R}^{2}$ & $\beta$ & $\mathbf{F}$ & $p^{\# \#}$ \\
\hline \multicolumn{7}{|l|}{ HGS } \\
\hline $\mathbf{C C}(\mathrm{cm})$ & 0.43 & $0.022 *$ & 0.19 & 0.649 & 5.969 & $0.022 *$ \\
\hline \multicolumn{7}{|c|}{ Flexor Carpi Radialis } \\
\hline RMSs (\%) & 0.23 & 0.243 & 0.05 & 0.084 & 1.428 & 0.243 \\
\hline IEMG $(\Omega)$ & 0.002 & 0.994 & $<0.0001$ & 0.005 & $<0.0001$ & 0.994 \\
\hline \multicolumn{7}{|l|}{ RESISFOR } \\
\hline $\mathbf{C C}(\mathrm{cm})$ & 0.44 & $0.026^{*}$ & 0.20 & 0.700 & 5.644 & $0.026^{*}$ \\
\hline \multicolumn{7}{|c|}{ Flexor Carpi Radialis } \\
\hline RMSs (\%) & -0.11 & 0.605 & 0.01 & -0.063 & 0.276 & 0.605 \\
\hline $\operatorname{IEMG}(\Omega)$ & 0.29 & 0.165 & 0.08 & 0.649 & 2.054 & 0.165 \\
\hline \multicolumn{7}{|l|}{ Biceps Brachii } \\
\hline RMSs (\%) & -0.23 & 0.281 & 0.05 & -0.122 & 0.221 & 0.281 \\
\hline IEMG $(\Omega)$ & 0.38 & 0.063 & 0.14 & 0.555 & 3.806 & 0.063 \\
\hline \multicolumn{7}{|l|}{ 30-s CST } \\
\hline $\mathbf{C C}(\mathrm{cm})$ & 0.53 & $0.004 *$ & 0.28 & 0.546 & 9.820 & $0.004 *$ \\
\hline \multicolumn{7}{|l|}{ Vastus Lateralis } \\
\hline RMSs (\%) & 0.24 & 0.231 & 0.06 & 0.126 & 1.506 & 0.231 \\
\hline IEMG $(\Omega)$ & 0.17 & 0.391 & 0.03 & 0.238 & 0.763 & 0.391 \\
\hline \multicolumn{7}{|l|}{ Vastus Medialis } \\
\hline RMSs (\%) & 0.31 & 0.122 & 0.09 & 0.166 & 2.562 & 0.122 \\
\hline IEMG $(\delta)$ & 0.10 & 0.618 & 0.01 & 0.196 & 0.255 & 0.618 \\
\hline \multicolumn{7}{|l|}{ Tibialis Anterior } \\
\hline RMSs (\%) & 0.19 & 0.347 & 0.04 & 0.070 & 0.921 & 0.347 \\
\hline IEMG $(\Omega)$ & 0.29 & 0.142 & 0.08 & 0.342 & 2.305 & 0.142 \\
\hline
\end{tabular}

$\mathrm{R}$ Pearson $=$ Pearson correlation coefficient; $\mathrm{p}^{\#}=$ significance level (Pearson correlation); $\mathrm{R}^{2}=$ determination coefficient; $\beta=$ regression coefficient; $\mathrm{F}=\mathrm{F}$ distribution $\left(\mathrm{F}\right.$ of Fisher-Snedecor); $\mathrm{p}^{\# \#}=$ significance level (simple linear regression); $*=\mathrm{p}<0.05$; $\mathrm{CC}=$ calf circumference; HGS = hand grip strength; RESISFOR = test of strength and endurance of the upper limbs; 30-s CST $=30$-second chair stand test; RMSs = root mean square standard; IEMG = integration EMG. Source: Authors.

Table 4 shows the multiple linear regression model for the HGS, RESISFOR test and 30-s CST in physically active elderly. The CC, the neural activity of the flexor carpi radialis muscle and the SES explained, altogether, $64.0 \%$ of the performance of PFA elderly in the HGS test. Although SES has been considered in the study as a potential modifier variable, it was not correlated with HGS $(\mathrm{p}=0.04)$ in the final model.

Only muscle mass remained significantly influencing on the performance of elderly women in the $30-\mathrm{s}$ CST $\left(\mathrm{R}^{2}{ }_{\mathrm{aj}}=\right.$ $0.39 ; \mathrm{p}=0.01)$. This increase of $11.0 \%$ in relation to the results of the bivariate analysis $\left(\mathrm{R}^{2}=0.28\right)$ is due to the adjustment by other variables considered for construction of the final model, such as the neural activity of the vastus lateralis, vastus medialis and tibialis anterior, among others (Table 4).

Table 4. Multiple Linear Regression Final Model for manual grip strength. RESISFOR test and 30-second chair stand test in elderly women practicing physical activity. Campina Grande/PB. Brazil. 2015.

\begin{tabular}{|c|c|c|c|c|}
\hline Model & $\mathbf{R}^{2}{ }_{\text {aj }}$ & $\beta$ & $p^{\# \#}$ & CI95\% \\
\hline HGS $^{1}$ & 0.64 & & & \\
\hline $\mathrm{CC}(\mathrm{cm})$ & & 0.503 & 0.030 & $0.056-0.950$ \\
\hline \multicolumn{5}{|l|}{ Flexor Carpi Radialis } \\
\hline IEMG $(J)$ & & -2.331 & 0.024 & $-4.299-0.362$ \\
\hline SES & & -0.371 & 0.041 & $-0.725--0.018$ \\
\hline 30-s CST ${ }^{2}$ & 0.39 & & & \\
\hline $\mathrm{CC}(\mathrm{cm})$ & & -0.442 & 0.011 & $-0.768--0.115$ \\
\hline
\end{tabular}

${ }^{1}$ HGS Model = adjusted to age, high blood pressure, diabetes and osteoarticular diseases; MMSE, BMI, RMSs.

${ }^{2} 30$-s CST Model = adjusted to high blood pressure and diabetes, age, SES, MMSE, BMI and RMSs of the vastus lateralis. vastus medialis and tibialis anterior.

$\mathrm{CC}=$ calf circumference; $\mathrm{IEMG}=$ integration $\mathrm{EMG} ; \mathrm{SES}=$ socioeconomic status; $\mathrm{MMSE}=$ Mini Mental State Exam; $\mathrm{BMI}=$ body mass index; RMSs = root mean square standard; $\mathrm{R}_{\mathrm{aj} .}^{2}=$ adjusted determination coefficient; $\beta$ = regression coefficient; $\mathrm{p}^{\text {\#\# }}=$ significance level (multiple linear regression); CI95\% $=$ Confidence interval of $95 \%$ (multiple linear regression); $*=p<0.05$. Source: Authors. 
Bivariate analysis showed no significant correlation of CC $(p=0.53)$ and neural activity of FCR $(p=0.11)$ and BB $(p$ $=0.34)$ muscles with the RESISFOR test.

The multiple linear regression model for HGS, RESISFOR and the 30-s CS tests in NPFA elderly is shown in Table 5. Only neural activity of the radial flexor carpi, adjusted for other variables of the study, showed a significant correlation with HGS ( $p=0.03$ ), explaining $35.0 \%$ of the generation of isometric strength in the arm. In the dynamic force test of the upper limb (RESISFOR), $66.0 \%$ of the performance was explained by muscle mass $(p<0.0001$ ), neural activity of the FCR muscle ( $p$ $=0.01)$ and BMI $(\mathrm{p}<0.0001)$. The final model was adjusted by BB muscle activity, prevalence of hypertension, age, SES, MMSE, and MBQE. No significant correlation was observed between any of the study variables with the performance of NPFA elderly in the 30-s CST.

Table 5. Multiple Linear Regression Final Model for manual grip strength. RESISFOR test and 30-second chair stand test in elderly women non-practicing physical activity. Campina Grande/PB. Brazil. 2015.

\begin{tabular}{|c|c|c|c|c|}
\hline Model & $\mathbf{R}^{2}{ }_{\text {aj }}$ & $\beta$ & $p^{\# \#}$ & CI95\% \\
\hline HGS $^{1}$ & 0.35 & & & \\
\hline \multicolumn{5}{|l|}{ Flexor Carpi Radialis } \\
\hline RMSs $(\%)$ & & 0.184 & 0.027 & $0.024-0.344$ \\
\hline RESISFOR $^{2}$ & 0.66 & & & \\
\hline $\mathrm{CC}(\mathrm{cm})$ & & 1.643 & $<0.0001$ & $0.934-2.351$ \\
\hline \multicolumn{5}{|l|}{ Flexor Carpi Radialis } \\
\hline RMSs (\%) & & -0.314 & 0.012 & $-0549--0.080$ \\
\hline BMI $\left(\mathrm{kg} / \mathrm{m}^{2}\right)$ & & -1.432 & $<0.0001$ & $-1.990--0.874$ \\
\hline
\end{tabular}

${ }^{1} \mathrm{HGS}$ Model $=$ adjusted to age, SES, high blood pressure and osteoarticular diseases; MMSE, BMI, CC e MBQE.

${ }^{2}$ RESISFOR Model = adjusted to high blood pressure, age, SES, MMSE, MBQE e RMSs of the biceps brachii muscle.

$\mathrm{CC}=$ calf circumference; $\mathrm{IEMG}=$ integration $\mathrm{EMG} ; \mathrm{SES}=$ socioeconomic status; $\mathrm{MMSE}=$ Mini Mental State Exam; $\mathrm{BMI}=$ body mass index; $\mathrm{MBQE}=$ modified Baecke Questionnaire for the Elderly; $\mathrm{RMSs}=$ root mean square standard; $\mathrm{R}_{\mathrm{aj} .}^{2}=$ adjusted determination coefficient; $\beta=$ regression coefficient; $\mathrm{p}^{\# \#}=$ significance level (multiple linear regression); $\mathrm{C} 195 \%=$ Confidence interval of $95 \%$ (multiple linear regression); $*=\mathrm{p}<0.05$. Source: Authors.

\section{Discussion}

Population aging is a global phenomenon and represents one of the major public health challenges (Brito et al., 2013). This is due to the increased susceptibility of the elderly to diseases and disorders that can lead to limitations in their physical performance and, consequently, functional dependence (Clouston et al., 2013). Muscle weakness is a major determinant of physical decline and, therefore, an important aspect of health assessment of the elderly (Reid et al., 2014). Studies have indicated changes in muscle mass (Foong et al., 2016; Eibich et al., 2016; Degens et al., 2021) and neuromuscular function (Hakkien et al., 2001; Radaelli et al., 2013; Arnold \& Bautmans, 2014; Sit et al., 2021) as the main components related to reduced muscle strength in the elderly. However, studies have investigated independent factors, not considering the concomitant effect of muscle and neuromuscular activity on muscle strength, as assessed in the present study.

In this study, it was observed that the PFA elderly obtained higher mean values in the RESISFOR test and 30-s CST when compared to NPFA elderly. A study conducted in Brazil evaluated the influence of a muscle strength training program on physical performance in elderly women. After 12 weeks, the effects of the program were compared among women undergoing training and women in a control group. The PFA women had higher mean values in dynamic muscle strength test of the right (27.1 repetitions) and left (27.4 repetitions) upper limb in the control group (25.3 and 25.1 repetitions, respectively) ( $\mathrm{p}<0.001)$. The PFA women had also higher mean values in 30-s CST (18.2 repetitions) compared to control (16.2 repetitions) (p <0.001) (Gerage et al., 2013).

A review and meta-analysis study evaluating the impact of training with resistance exercise on muscle strength 
showed overall significant positive effects on muscle strength and physical performance (Bao et al., 2020). The results of this study, and others, indicate greater muscle strength dynamics (Bao et al., 2020; Syed-Abdul, 2020) and lack of significant difference in HGS associated with physical exercise (Seco et al., 2013; Bann et al., 2015). This difference observed between the isometric muscle strength (HGS) and the dynamic muscle strength (RESISFOR and 30-s CST) may be due to neuromuscular differences involved in isometric and dynamic contractions for the production of muscle strength (Kallio et al., 2014). To produce the same muscle workload, dynamic and isometric activities provide different stimuli to the muscles. These differences are related to activation and discharge patterns of motor units (Kallio et al., 2014) and muscle synergistic activity (Mohr et al., 2015).

The dynamic contractions involve changes in length of several synergistic muscles for producing motion and thus require more discharges in synchronization of motor units when compared to isometric contractions. Movements that require more than one muscle activity also exhibit greater synchronization of intramuscular motor units, such as the activities that use dynamic contractions, facilitating more precise control of the joint torque (Mohr et al., 2015). Therefore, it is suggested that activities that require dynamic contractions generate greater muscular strength. This would explain the lower strength seen in NPFA elderly. As they do not practice exercise, have lower muscular activity, and consequently less strength in relation to PFA elderly women. This behavior of motor units in dynamic and isometric activities can explain also the observed difference in neuromuscular function among PFA and NPFA elderly during the RESISFOR test.

In bivariate analysis of muscle and neuromuscular function with the HGS, there was significant correlation between $\mathrm{CC}$ and HGS in both groups. In multivariate analysis, in addition to CC, the neural activity of the FCR muscle showed significant and independent correlation with the HGS of PFA women. In the multiple model for NPFA elderly, the CC lost statistical significance and only neural activity of the FCR muscle remained significantly related to the HGS.

In a study carried out in the Netherlands with elderly submitted to a 24-week training program, there was bivariate significant correlation of muscle mass with the HGS in the group submitted to physical exercises $(p<0.001)$ and in the control group ( $\mathrm{p}$ <.001) (Mohr et al., 2015). Another study with elderly evaluated the effects of low and high intensity resistance training on the muscle strength and neuromuscular function of the biceps muscle during maximal isometric contraction (one repetition maximum). After 12 weeks of training, there was a significant increase in neuromuscular activity in the elderly undergoing the training program. It was observed also that those undergoing a high-intensity program showed greater neuromuscular activity compared to the group submitted to low intensity exercise Sit et al., 2021).

Among the PFA elderly of this study, there was no influence of muscle and neuromuscular activity in the RESISFOR test. Among the NPFA elderly, in the multiple analyses, besides the relation with the muscle mass observed in the bivariate analysis, the FCR muscle activity also showed to be related with the dynamic strength of the upper limb. The final model was adjusted by BB muscle activity, although independent relation with the RESISFOR test was not observed.

Study carried out with elderly women evaluated the effect of a training program with exercises of physical resistance on the neuromuscular activity of the BB muscle while performing dynamic movements of the elbow. After 13 weeks of training, there was no increased neuromuscular activity of the BB muscle but there was a significant improvement in muscle strength (Radaelli et al., 2013). The fact that neuromuscular activity did not increase concomitant to improved muscle strength suggests that there is no linear relationship between the two functions, what differs from what was observed in the present study, and that other factors are associated with the gain in muscle strength.

The influence of the FCR muscle in the dynamic muscular strength of the NPFA group may be due to the type of test performed in this study, which consisted in keeping the dominant upper limb extended along the body without support elbow, perpendicular to the ground. The elderly should hold a dumbbell of $2 \mathrm{~kg}$, conducting a complete flexion and extension of the 
elbow. This position could explain the increased activation of FCR muscle, related to the strength carried by the hand, compensating for the BB muscle activity in the elbow flexion movement.

In this study, we observed a significant correlation between muscle mass with the 30-s CST in the PFA elderly. This correlation persisted in the multivariate analysis adjusted for other variables, including the neuromuscular activity of the vastus lateralis, vastus medialis and tibialis anterior. In the NPFA group, the final model showed no significant correlation of muscle mass and neuromuscular function with the 30-s CST.

In Finland, the effects of a resistance training program on muscle fibers (antigravity and fast twitch) of the VL and VM muscles during knee extension were evaluated. After six months of training, there was a significant increase in muscle strength both muscles ( $p<0.001)$ and size of muscle fibers type I ( $p<0.05)$ and type II ( $p<0.05)$ of elderly women. However, significant correlation was found between hypertrophy of muscle fibers type II (fast twitch) and dynamic strength (Hakkien et al., 2001).

A systematic review and meta-analysis evaluated the influence of neuromuscular activity on muscle strength in elderly undergoing resistance training programs. Muscle strength was observed for knee extension and plantar flexion of the ankle. Of the 17 studies selected in the review, only two reported significant relationship between greater neuromuscular activity of the VL, VM and lateral vastus, and gain of muscle strength in the lower limbs in PFA elderly. These studies also verified gains in neuromuscular activity and muscle strength after physical exercise. However, there was no significant relationship between more neuromuscular activity and increasing strength (Arnold \& Bautmans, 2014). The lack of relationship between neuromuscular activity and muscle strength of the lower limbs, after a certain period of training, seems to be related to other factors, not just to neuromuscular activity.

Thus, different results are observed for the relationship between muscle mass and neuromuscular function according to the tests of muscle strength adopted in the case of both, elderly and non-practitioners practitioners of physical activity.

The mechanism involved in the generation of muscular strength seems to have different associated factors. Initially, muscle mass was considered the main determinant of an individual's ability to generate muscle strength, what can be attributed to the importance of skeletal muscle in the generation of strength and, therefore, it is critical for activities that require joint movement(KF et al., 2014). Furthermore, studies evaluating the aging process have observed that limitations in the successful development of muscle strength are associated with changes in muscular level, such as atrophy and loss of rapid contraction muscle fibers, glycation of proteins and insulin resistance (Wiedmer et al., 2021).

However, a non-linear relationship between muscle mass and strength has been reported. Strength decline has been greater than that of muscle mass, indicating that mass is not the only factor associated with loss of muscle strength in the elderly (Zembrón-Lancy et al., 2014; Wiedmer et al., 2021). This discrepancy in the relationship between the decline in muscle strength and reduced muscle mass seems to also involve the action of other systems, as observed in this study. When considering other factors, along with muscle mass, there was a significant contribution of neural activity in the production of muscle strength in isometric strength test (PFA and NPFA) and dynamic strength testing of the upper limbs (NPFA) and lower (PFA), which suggests a role of the nervous system on the development of muscle strength.

Neuromuscular activity is responsible for the speed of muscle contraction and, therefore, changes that influence the discharge properties of motor units or reduce the size and amount of units recruited for movement may affect the ability to produce acceleration and power in the joints, reducing the elderly performance, particularly in activities that require fast movements or higher level of effort (Zembrón-Lancy et al., 2014; Wiedmer et al., 2021). However, just as it happens to muscle mass, neuromuscular activity does not seem to be the only determining factor in reducing the strength. Therefore, reduction of muscle strength seems to be mainly a result of the combination of the deficits of both functions (Reid et al., 2014). 
In the assessment of the effects of exercise on muscle strength in the elderly, an increase in EMG rates during the first three months of training was noticed (Hakkien et al., 2001). This indicates that the initial increase in muscle strength is largely related to increased neuromuscular activation of agonist muscles undergoing training (Kraemer et al., 2001). The mechanism involved in this process appears to be related to an increase in synchronization of activation of motor units, that is, time and frequency of electrical shocks (Kallio et al., 2014). After the first months, other mechanisms such as reducing the co-activation of antagonistic muscles seem to contribute to increased muscle strength (Latash, 2018). This could have explained the lower independent influence of neural activity in PFA elderly of this study, especially in dynamic strength testing, as this was a cross-sectional study.

In addition to peripheral neural activity, the role of the primary motor cortex (M1) in the regulation of muscle strength has recently been reported, to check the possible influence of central neuronal degeneration in appendicular muscle weakness that takes place with increasing age (Plow et al., 2013; Clark et al., 2015).

Study comparing young adults and elderly people evaluated the role of central neural activity in the bending strength of the biceps. It was observed that the elderly had higher excitability of the motor cortex in relation to young people, indicating higher central neuronal activity during voluntary muscle contraction at older ages (Plow et al., 2013). With this increase in the excitability of cortical neurons, there is increased recruitment of motor neurons (spinal cord) to increase muscle activation and consequently generate more force (Clark et al., 2015). However, when looking at the relationship between cortical excitability and muscle strength in the elderly, it was found that weaker elderly could not keep this compensatory effect. They had reduced excitability (Plow et al., 2013) and, therefore, they were not able to modulate their corticospinal excitability at different strength levels (Clark et al., 2015). These data suggest that there is a compensatory cortical effect to the reduction of certain amount of muscular strength, which is not maintained when this is exceeded. The reason for this question remains unanswered.

This study has limitations on the influence of the type of physical activity and its relationship to muscle strength, since physically active elderly participants were not stratified by type of exercise (strength and general fitness). This, however, does not compromise the results because the benefits of resistance training programs are well known and described in the literature. Therefore, a joint analysis of different physical activities would make it possible to assess more comprehensively the relationship of muscle and neuromuscular function with isometric muscle strength and momentum in these older women.

Another possible limitation comes from the failure to assess energy expenditure of these elderly in daily life and leisure activities, as assessed between NPFA. Thus, it was not possible to compare the energy expenditure between the two groups neither to control models for PFA elderly for that variable because such activities are related to muscle strength and joint range of motion and can influence the dynamic tests. On the other hand, the inclusion of this variable in the assessment of NPFA elderly women allowed better control of data, as, because they are active and independent, they have daily energy expenditure, not necessarily linked to the practice of regular exercise, such as the related expense to domestic activities.

\section{Conclusion}

The comparison of PFA and NPFA elderly showed better results in dynamic muscle strength tests and greater neural activity of the FCR and BB muscles (during the dynamic test of strength for the upper limb) for the first. Muscle mass did not differ between groups. With regard to factors related to muscle strength, there were different results on the correlation of muscle mass and neuromuscular activity with strength in each test, indicating that there are physiological differences for each strength exercise applied to older women.

The data observed in this study provide information on the physical health of the elderly and show that physical exercise was relevant for better results of dynamic force among elderly women, an important factor for the execution of 
essential movements of daily activities and maintenance of range of motion. Thus, the development of strategies to maintain and/or recover muscle strength is suggested. They can be developed through global exercise programs and by prescribing individualized and specific home exercises for the muscle groups compromised. These actions would contribute to reduce physical limitations, promoting maximum independence, reducing the worsening of chronic conditions and the need for hospitalization related to muscle weakness.

\section{Acknowledgments}

This study was financed in part by the Coordenação de Aperfeiçoamento de Pessoal de Nível Superior Brasil (CAPES).

\section{References}

Associação Brasileira de Empresas e Pesquisas. (2020). Critério Brasil - ABEP. Associação Brasileira de Empresas e Pesquisas Website. https://www.abep.org/criterio-brasil.

Arnold, P., \& Bautmans, I. (2014). The influence of strength training on muscle activation in elderly persons: a systematic review and metaanalysis. Experimental gerontology, 58, 58-68. https://doi.org/10.1016/j.exger.2014.07.012.

Angulo, J., El Assar, M., Álvarez-Bustos, A., \& Rodríguez-Mañas, L. (2020). Physical activity and exercise: Strategies to manage frailty. Redox biology, 35, 101513. https://doi.org/10.1016/j.redox.2020.101513.

Bann, D., Hire, D., Manini, T., Cooper, R., Botoseneanu, A., McDermott, M. M., Pahor, M., Glynn, N. W., Fielding, R., King, A. C., Church, T., Ambrosius, W. T., Gill, T. M., \& LIFE Study Group (2015). Light Intensity physical activity and sedentary behavior in relation to body mass index and grip strength in older adults: cross-sectional findings from the Lifestyle Interventions and Independence for Elders (LIFE) study. PloS one, 10 (2), e0116058. https://doi.org/10.1371/journal.pone.0116058.

Bao, W., Sun, Y., Zhang, T., Zou, L., Wu, X., Wang, D., \& Chen, Z. (2020). Exercise Programs for Muscle Mass, Muscle Strength and Physical Performance in Older Adults with Sarcopenia: A Systematic Review and Meta-Analysis. Aging and Disease, 11(4), 863. JKL International LLC. /pmc/articles/PMC7390512/.

Clark, B. C., Taylor, J. L., Hong, S. L., Law, T. D., \& Russ, D. W. (2015). Weaker Seniors Exhibit Motor Cortex Hypoexcitability and Impairments in Voluntary Activation. The journals of gerontology. Series A, Biological sciences and medical sciences, $70(9)$, $1112-1119$. https://doi.org/10.1093/gerona/glv03

Brito, M. da C. C., Freitas, C. A. S. L., Mesquita, K. O. de, \& Lima, G. K. (2013). Envelhecimento Populacional e os Desafios para a Saúde Pública: Análise da Produção Científica. Revista Kairós-Gerontologia, 16(2), 161-178. https://revistas.pucsp.br/index.php/kairos/article/view/1855.

Brucki, S. M. D., Nitrini, R., Caramelli, P., Bertolucci, P. H. F., \& Okamoto, I. H. (2003). Sugestões para o uso do mini-exame do estado mental no Brasil. Arquivos de Neuro-Psiquiatria, 61(3 B), 777-781. http://www.scielo.br/j/anp/a/YgRksxZVZ4b9j3gS4gw97NN/?lang=pt.

Clouston, S. A., Brewster, P., Kuh, D., Richards, M., Cooper, R., Hardy, R., Rubin, M. S., \& Hofer, S. M. (2013). The dynamic relationship between physical function and cognition in longitudinal aging cohorts. Epidemiologic reviews, 35(1), 33-50. https://doi.org/10.1093/epirev/mxs004.

Degens, H., Attias, J., Evans, D., Wilkins, F., \& Hodson-Tole, E. (2021). The mobility limitation in healthy older people is due to weakness and not slower muscle contractile properties. PLOS ONE, 16(6), e0253531. Public Library https://journals.plos.org/plosone/article?id=10.1371/journal.pone.0253531.

Eibich, P., Buchmann, N., Kroh, M., Wagner, G. G., Steinhagen-Thiessen, E., Demuth, I., \& Norman, K. (2016). Exercise at Different Ages and Appendicular Lean Mass and Strength in Later Life: Results From the Berlin Aging Study II. The journals of gerontology. Series A, Biological sciences and medical sciences, 71(4), 515-520. https://doi.org/10.1093/gerona/glv171.

Foong, Y. C., Chherawala, N., Aitken, D., Scott, D., Winzenberg, T., \& Jones, G. (2016). Accelerometer-determined physical activity, muscle mass, and leg strength in community-dwelling older adults. Journal of cachexia, sarcopenia and muscle, 7(3), 275-283. https://doi.org/10.1002/jcsm.12065.

Gerage, A. M., Januário, R. S. B., Nascimento, M. A. do, Pina, F. L. C., \& Cyrino, E. S. (2013). Impact of 12 weeks of resistance training on physical and functional fitness in elderly women. Revista Brasileira de Cineantropometria \& Desempenho Humano, 15(2), 145-154. Universidade Federal de Santa Catarina. http://www.scielo.br/j/rbcdh/a/fxfNz5DP67BWLDK993MBkCL/?lang=en.

Häkkinen, K., Kraemer, W. J., Newton, R. U., \& Alen, M. (2001). Changes in electromyographic activity, muscle fibre and force production characteristics during heavy resistance/power strength training in middle-aged and older men and women. Acta physiologica Scandinavica, 171(1), 51-62. https://doi.org/10.1046/j.1365-201X.2001.00781.x.

Jones, C. J., Rikli, R. E., \& Beam, W. C. (1999). A 30-s chair-stand test as a measure of lower body strength in community-residing older adults. Research quarterly for exercise and sport, 70(2), 113-119.https://doi.org/10.1080/02701367.1999.10608028. 
Kallio, J., Søgaard, K., Avela, J., Komi, P. v., Selänne, H., \& Linnamo, V. (2014). Motor unit discharge rate in dynamic movements of the aging soleus. Frontiers in Human Neuroscience, 8(SEP), 1-4. Frontiers Media SA. /pmc/articles/PMC4179534/.

Kirkwood T. (2017). Why and how are we living longer? Experimental physiology, 102(9), 1067-1074. https://doi.org/10.1113/EP086205.

Larsson, L., Degens, H., Li, M., Salviati, L., Lee, Y. I., Thompson, W., Kirkland, J. L., \& Sandri, M. (2019). Sarcopenia: Aging-Related Loss of Muscle Mass and Function. Physiological reviews, 99(1), 427-511. https://doi.org/10.1152/physrev.00061.2017.

Latash, M. L. (2018). Progress in Motor Control: Muscle coactivation: definitions, mechanisms, and functions. Journal of Neurophysiology, $120(1), 88$. American Physiological Society. from /pmc/articles/PMC6093955/.

Lohman, T. (1988). Anthropometric Standardization Reference Manual. Champaign(IL)Title. Champaign IL: Human Kinetics Books.

Mohr, M., Nann, M., von Tscharner, V., Eskofier, B., \& Nigg, B. M. (2015). Task-Dependent Intermuscular Motor Unit Synchronization between Medial and Lateral Vastii Muscles during Dynamic and Isometric Squats. PloS one, 10(11), e0142048. https://doi.org/10.1371/journal.pone.0142048.

Milanović, Z., Pantelić, S., Trajković, N., Sporiš, G., Kostić, R., \& James, N. (2013). Age-related decrease in physical activity and functional fitness among elderly men and women. Clinical interventions in aging, 8, 549-556. https://doi.org/10.2147/CIA.S44112.

Osness, W. H. (Wayne H., \& Council on Aging and Adult Development (U.S.). (1990). Functional fitness assessment for adults over 60 years : a field based assessment, 24. American Alliance for Health, Physical Education, Recreation, and Dance, Association for Research, Administration, Professional Councils, and Societies, Council on Aging and Adult Development.

Paulo, S. (2009). "Reprodutibilidade e Validade do Questionário de Atividade Física Habitual de Baecke Modificado em Idosos Saudáveis." http://www.livrosgratis.com.br.

Peter, M. (2018). ACSM's Resources for The Exercise Physiologist. (L. Randi, K. W. Marcus, \& S. E. James, Eds.). Wolters Kluwer.

Plow, E. B., Cunningham, D. A., Bonnett, C., Gohar, D., Bayram, M., Wyant, A., Varnerin, N., Mamone, B., Siemionow, V., Hou, J., Machado, A., \& Yue, G. H. (2013). Neurophysiological correlates of aging-related muscle weakness. Journal of neurophysiology, 110(11), 2563-2573. https://doi.org/10.1152/jn.00205.2013.

Rantanen, T., Masaki, K., Foley, D., Izmirlian, G., White, L., \& Guralnik, J. M. (1998). Grip strength changes over 27 yr in Japanese-American men. Journal of applied physiology (Bethesda, Md.: 1985), 85(6), 2047-2053. https://doi.org/10.1152/jappl.1998.85.6.2047.

Radaelli, R., Botton, C. E., Wilhelm, E. N., Bottaro, M., Lacerda, F., Gaya, A., Moraes, K., Peruzzolo, A., Brown, L. E., \& Pinto, R. S. (2013). Low- and highvolume strength training induces similar neuromuscular improvements in muscle quality in elderly women. Experimental gerontology, $48(8), 710-716$. https://doi.org/10.1016/j.exger.2013.04.003.

Reid, K. F., Pasha, E., Doros, G., Clark, D. J., Patten, C., Phillips, E. M., Frontera, W. R., \& Fielding, R. A. (2014). Longitudinal decline of lower extremity muscle power in healthy and mobility-limited older adults: influence of muscle mass, strength, composition, neuromuscular activation and single fiber contractile properties. European journal of applied physiology, 114(1), 29-39. https://doi.org/10.1007/s00421-013-2728-2.

Santos, V. R. dos, Araújo, M. Y. C., Cardoso, M. R., Batista, V. C., Chistofaro, D. G. D., \& Gobbo, L. A. (2017). Association of insufficient physical activity with sarcopenia and sarcopenic obesity in individuals aged 50 years or more. Revista de Nutrição, 30(2), 175-184. http://www.scielo.br/j/rn/a/pLknZVPj5tXK7krNycDGmWp/?lang=en.

Seco, J., Abecia, L. C., Echevarría, E., Barbero, I., Torres-Unda, J., Rodriguez, V., \& Calvo, J. I. (2013). A long-term physical activity training program increases strength and flexibility, and improves balance in older adults. Rehabilitation nursing: the official journal of the Association of Rehabilitation Nurses, 38(1), 37-47. https://doi.org/10.1002/rnj.64.

Sit, R. W. S., Choi, S. Y. K., Wang, B., Chan, D. C. C., Zhang, D., Yip, B. H. K., \& Wong, S. Y. S. (2021). Neuromuscular exercise for chronic musculoskeletal pain in older people: a randomised controlled trial in primary care in Hong Kong. British Journal of General Practice, 71(704), e226-e236. British Journal of General Practice. Retrieved October 17, 2021, from https://bjgp.org/content/71/704/e226.

Syed-Abdul, M. M. (2020). Benefits of Resistance Training in Older Adults. Current Aging Science, 14(1), 5-9. Bentham Science Publishers Ltd.

Tomás, M. T., Galán-Mercant, A., Carnero, E. A., \& Fernandes, B. (2018). Functional Capacity and Levels of Physical Activity in Aging: A 3-Year Followup. Frontiers in medicine, 4, 244. https://doi.org/10.3389/fmed.2017.00244.

The SENIAM project (Surface ElectroMyoGraphy for the Non-Invasive Assessment of Muscle). (2006). Determination of sensor location. The SENIAM Project Website. http://seniam.org/sensorlocation.htm.

Wiedmer, P., Jung, T., Castro, J. P., Pomatto, L. C. D., Sun, P. Y., Davies, K. J. A., \& Grune, T. (2021). Sarcopenia - Molecular mechanisms and open questions. Ageing Research Reviews, 65, 101200. Elsevier.

Zembroń-Łacny, A., Dziubek, W., Rogowski, Ł., Skorupka, E., \& Dąbrowska, G. (2014). Sarcopenia: monitoring, molecular mechanisms, and physical intervention. Physiological research, 63(6), 683-691. https://doi.org/10.33549/physiolres.932692 